\title{
تقارير هؤتمرات
}

\section{الملتقى العربي الثاني للوصول الحر \\ 2021 / 10 / 21 - 19}

\section{أ.د. عبدالرحهن فراج}

\section{أسـاذ بقسيـم علوم المعلومات \\ جامعة بني سـويف}

أصبح الوصول الحر للمعلومات Open Access دعوة عالمية يقف وراءها عديد من المؤسسات الدولية والوطنية، وهي دعوة لإتاحة النتاج الفكري العلمي والبحثي لجميع المستفيدين والمهتمين، بصورة حرة خالية من القيود ذات الصلة، وقد تطورت هذه الدعوة إلى Open إتاحة جميع ممارسات دورة البحث العلمي بصيورة حرة فيما يسمى بالعلم المفتوح Science

وقد أقيم الملتقى العربي الثاني للوصول الحر، متزامنا مع الأسبوع العالمي للوصول الحر للمعلومات International Open Access Week، وبالشراكة بين المنظمة العربية للتربية والثقافة والعلوم (ألكسو) والمجموعة العربية للوصول الحر (أكوا)، على مدى ثلاثة أيام، من الثلاثاء إلى الخميس 2021/10/21-19م، وذلك بصورة افتراضية عبر منصة "زووم". وأقيمت في الملتقى 6 جلسات علمية ألقي فيها 30 بحثًا علميًا، و3 جلسات للمتحدثين الرئيسيين، كما عقدت مائدتان مستديرتان، و6 ورش عمل وزعت على أيام الملتقى. ومثل جميع المشاركين في الملتقى المؤسسات الدولية والعربية الأكاديمية والعلمية والبحثية والحكومية 
التالية: الدليل العالمي لدوريات الوصول الحر (DOAJ)، والمنظمة العربية للتربية والثقافة والعلوم (ألكسو)، ومؤسسة محمد بن راشد آل مكتوم للمعرفة (دبي، الإمارات)، والمركز الإقليمي لتكنولوجيا المعلومات والاتصال- يونسكو (البحرين)، والمجلس العربي للعلوم الاجتماعية (لبنان)، والمجلس الأعلى للسكان (الأردن)، والمركز الوطني الجامعي للتوثيق العلمي والتقني (تونس)؛ ومركز مدى (قطر)، ووزارة التربية والتعليم (فلسطين)؛ ومركز فاعلون (الجزائر)، ومكتبة الكويت الوطنية (الكويت)، والمكتبة الطبية ومكتبة كلية الاقتصاد والعلوم السياسية بجامعة السلطان قابوس (عُمان)، والمكتبات الجامعية بالجامعة الإسلامية (لبنان)، ومؤسسة الرؤية المصرية الأولى (مصر)، ومركز ضمان الجودة والاعتماد- جامعة بني سويف (مصر). وقد شارك في الملتقى 13 دولة عربية ودولة إسلامية من خلال ممثليها من الباحثين ومقدمي ورش من الجامعات العربية المشاركة في الملتقى: جامعة تونس الافتراضية (تونس)، وجامعتا الملك عبدالعزيز وجامعة طيبة (السعودية)، وجامعة السلطان قابوس (سلطنة عُمان)، والجامعة المستنصرية (العراق)، وجامعة الشـارقة (الإمارات)، ومدرسة علوم المعلومات (المفرب)، وجامعة دمشق (سوريا)، وجامعة البلقاء التطبيقية (الأردن)، وجامعة الخرطوم (السودان)، وجامعة النجاح الوطنية (فلسطين)، وجامعتا بني الوليد وطرابلس (ليبيا)، وجامعة المدينة العالمية (ماليزيا)، وجامعات: القاهرة، والأزهر، والأسكندرية، وبني سويف، والمستقبل

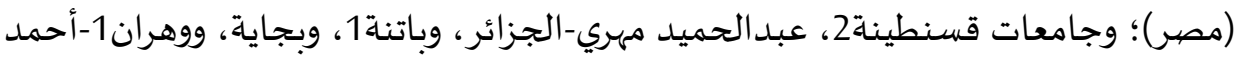
بن بلة، وأدرار الجزائر، والجزائر-2 أبو القيام سعدالله، والجزائر-3 (الجزائر). ومثَّل الباحثون والمشاركون تخصصات: العلوم الاجتماعية، والعلوم الطبية، والكيمياء، والأنثروبولوجيا والإثنوجرافيا، وعلم السكان، والتربية والمصادر التعليمية، وعلم الحاسبات، والمكتبات والمعلومات، وغيرها من التخصصيات العلمية. وقد أُلقي في الجلسة الختامية للملتقى، "البيان العربي للعلم المفتوح"، والذي سيُطرح على موقع الملتقى للتوقيع عليه من قبل العلماء والباحثين والمؤسسات العربية البحثية والأكاديمية. 
الملتقى العربى الثانى للوصول الحر

وانتهى الملتقى للتوصيات التالية، والتي نضعها تحت نظر المؤسسات البحثية والأكاديمية والحكومية العربية، وصُناع السياسات والمسؤولين المعنيين:

العناية بترجما "البيان العربي للعلم المفتوح" الذي تبناه الملتقى، إلى اللغتين الإنجليزية والفرنسية، ونشره وتوزيعه على أوسع نطاق. العناية بإعداد سياسـة عربية موحدة، وسياسات وطنية لكل دولة عربية على حدة، بشأن الوصول الحر وجميع ممارسات العلم المفتوح؛ كما أن هناك حاجة إلى إصدار البيانات

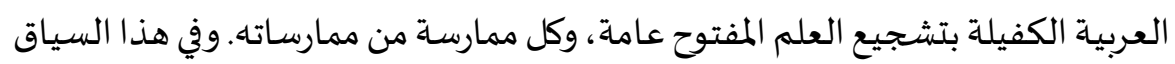
لابد من العناية بإنشاء منصية السياسات العبية للوصول الحر والعلم المفتوح. العناية بإنشاء المرصد العربي للعلم المفتوح Arab Open Science Monitor ، وذلك للتعرف على اتجاهات العلم المفتوح ومدى تقدمه على صعيد المجتمع العربي، ومحاولة تحسين الممارسات محل هذه المؤشرات، وإنشاء بعضها من الأسـاس. العناية بإنشاء السحابة العربية للعلم المفتوح Arab Open Science Cloud، وذلك لإتاحة البيانات والأدوات والخدمات البحثية، وإمكانية البحث والمشاركة فيها، وإعادة استخدا مها، للأغراض التعليمية والبحثية والابتكار. مع توافر بعض المستودعات الرقمية العبيية، سواء المؤسساتية أم التخصصية، هناك حاجة لإتاحة هذه المستودعات عبر منصة إلكترونية موحدة. لابد من إتاحة البيانات الخاصة بالبحوث العربية وفقا لمبادئ FAIR، وبصفة خاصة، هناك حاجة إلى إنشاء مزيد من مستودعات البيانات، أو تشجيع إتاحة البيانات ومشـاركتها عبر مستودعات المطبوعات، وعبر الدوريات المتخصصة، وإعداد السياسات الداعمة لذلك. فضلا عن وجود حاجة بالطبع لإنشاء دوريات للبيانات Data journals. فضلا عن وجوب العناية بإنشاء أدلة جامعة للدوريات والمستودعات المتاحة وفقا للوصول الحر، ومستودعات البيانات، فإنه تنبغي العناية أيضا بإنشاء منصات للمكونات الأخرى التي تمثل العلم المفتوح، ومنها: 
O منصات للتسجيل المسبق للدراسات العلمية Pre-registration. O منصات التحكيم العلمي المفتوح لها Open Peer Review، وممارسة التحكيم المفتوح

$$
\text { عبر منصات الدوريات ذاتها. }
$$

Open Source Software \& منصات للبرمجيات والأجهزة مفتوحة المصددر O .Hardware O منصات للمشاركة المفتوحة من قبل المواطنين في النشاط العلمي وهو ما يُدعى بالعلم التشاركي Citizen Science. إعداد توجيهات إلزامية للباحثين لإتاحة منشوراتهم العلمية وفقاً لسياسة الوصهول الحر، وذلك من قبل مؤسساتهم البحثية والأكاديمية. تسخير الإمكانات الكامنة في الموارد التعليمية المفتوحة لتكون قابلة للنفاذ للجميع، واتاحة ومشاركة الموارد التعليمية المفتوحة الشـاملة عبر منصات مركزية مخصصية للغرض. وفي هذا السياق، ينبغي دعم الشبكة العربية للموارد التعليمية المفتوحة التي طورتها الالكسو (www.alecso.org/oer) ودعوة الباحثين والمدرسين العرب إلى نشر مواردهم

$$
\text { فيها. }
$$

هناك حاجة لتطوير مستودعات موضوعية وفقا للتخصصيات المختلفة، وذلك من قبل

$$
\text { الجمعيات العلمية وأكاديميات البحث العلمي. }
$$

تبني أسلوب مسودات البحوث لتكون جزءًا من نظام النشر والإتاحة في البيئة العربية ومنحها الشرعية والمكانة والإطار القانوني الذي يحميها. مراجعة جودة المستودعات الرقمية المؤسساتية والتخصصية من خلال التحديث وتوفير الإحصاءات وتوفير سياسة واضحة للنشر في المستودعات الرقمية حتي لا يقع الباحثون

$$
\text { في فخ السرقات العلمية. }
$$

العمل على رقمنة الأعمال العلمية والأدبية والثقافية، مثل المخطوطات والموسوعات وغيرها من المصادر المرجعياة، وإتاحتها على منصيات للوصيول الحر. 
الملتقى العربى الثانى للوصول الحر

التعريف برخص الإبداع المشاع وكيفية استخدا امها من قبل الباحثين وغيرهم من المهتمين الراغبين في النشر الحر لأبحاثهم وأعمالهم الإبداعية. ضرورة تطوير أساليب تقنية ونصوص قانونية من شأنها ضبط البيئة الرقمية غير الآمنة، تلافي ظاهرة الانتحال والسرقة العلمية. تعزيز معرفة الباحثين بضوابط ومتطلبات النشر الدولي خاصة النشر الحر. لابد من الدعم الحكومي للنشر في دوريات الوصول الحر للمعلومات والمستودعات الرقمية والتشجيع على ذلك. النظر في نموذج جديد خاص بتمويل ودعم قطاعي التعليم والبحث العلمي بحث يتسنى من خلال هذا النموذج الموازنة ما بين حقوق المؤلفين في الانتفاع والاستثمار المادي من بن ابداعاتهم ومؤلفاتهم من جهة وكذا ضمان حق المستفيدين في الوصول الحر لهذه الابداعات والمنشورات. العمل علي إنشاء منصة إلكترونية تشمل جميع المكتبات الوطنية العبية وجميع أنماط

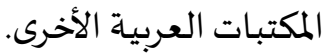
هناك حاجة لتشجيع المكتبات العربية، والأكاديمية منها بصفة خاصةة، للمشاركة في حركة الوصول الحر والعلم المفتوح بجميع ممارساته، وبصفة خاصية إعداد برامج تخصصية في الثقافة المعلوماتية للتعرف على المهارات والجدارات المؤهلة للانخراط في ممارسات العلم المفتوح.

لابد من حضور مقررات للوصول الحر والبيانات المفتوحة والعلم المفتوح في الأقسام الأكاديمية بالجامعات العربية وبصفة خاصية تخصصيات الحاسبات وتقنيات المعلومات والمكتبات.

ينبغي تشجيع إعداد الدراسات المنهجية حول اتجاهات الباحثين، والمؤسسات البحثية والدوريات العلمية والمسؤولين المعنيين، نحو العلم المفتوح وكل ممارسة من ممارساته، مثل الوصول الحر والبيانات البحثية المفتوحة والمصادر التعليمية المفتوحة؛ وتوجيه 
المنح البحثية الممولة من الجهات الحكومية أو الخاصة لهذا الأمر. كما أن هناك حاجة بطبيعة الحال لإعداد مراجعات علمية عن الدراسات العربية المنجزة حتى الآن حول اتجاهات الباحثين نحو الممارسات المختلفة للعلم المفتوح.

العناية بإعداد التقرير العربي لتقييم البحث العلمي Arab research assessment (ARA، لرصددوالتعرف على البنى الأساس للبحث العلمي والتقني، بجميع أركانه، في المجتمع العربي. العناية بتحفيز الباحثين ومكافأتهم على الانخراط في الوصول الحر والعلم المفتوح، وتصميم وتنفيذ وهيكلة الحوافز المشجعة على النشر والإتاحة وفقا للوصول الحر وليس فقط لمن حصل على معاملات تأثير وفقًا لنشره في الدوريات المقيدة. 